\title{
Development of teaching expertise viewed through the Dreyfus model of skill acquisition
}

\begin{abstract}
Lucinda J. Lyon ${ }^{1}$
Abstract: This study was designed to explore development of skill acquisition in dental education, utilizing the Dreyfus and Dreyfus continuum. By identifying what skill progression may be recognized in the expert dental educator and what experiences appear to influence this growth, the knowledge gained may inform more efficient, effective faculty support, development and life-long learning. Employing a qualitative approach, individual interviews were conducted with experienced educators and analyzed. Open coding of responses revealed that skill acquisition necessary to good teaching, as expressed by these experienced educators, reflects common themes and a learning curve similar to that noted by Dreyfus and Dreyfus and other investigators. In addition, to supporting knowledge and technique development, dental faculty described working to share with students a wide range of non-cognitive competencies such as professionalism, communication, and an ethic of care and service. Findings increase understanding of teaching skill acquisition in dental education and may help provide support for health care faculty who desire to become excellent educators.
\end{abstract}

Keywords: skill acquisition, teaching methods, novice to expert, expertise, reflection

\section{Introduction and Purpose}

Former Cornell University President Frank Rhodes spoke to the inspirational nature of teaching when he powerfully described:

Because of its profound impact upon both the individual student and society, teaching can never be just a job, however demanding; not even a career, no matter how professional. To the best professors, teaching is a moral vocation. It is moral because it seeks to develop not only comprehension, but also commitment; it influences and shapes not only the intellect, but also the will; it involves the cultivation of not only the mind, but also the heart ... it is a vocation because it is a calling and not simply a job.

Great teaching still has the power to inspire, to encourage critical but open outlook, a breadth of interest and a generosity of sprit. And students are challenged and inspired not by these qualities in the abstract, but by their embodiment in the professor (Rhodes, 2001, p. 67).

Today's most talented dental educators hope to make this impact on students. In pursuit of this goal, they embrace peer-reviewed standards, innovative teaching methods, topically integrated content, competency-based learning, authentic outcomes assessment, state-of-the-art simulation technology, and a growing commitment to interprofessional practice, and life-long

\footnotetext{
${ }^{1}$ University of the Pacific, Arthur A. Dugoni School of Dentistry, clyon@pacific.edu
} 
learning (American Dental Education Association Commission on Change and Innovation in Dental Education, 2009; Hendricson, et al., 2007). Dental faculty are called upon to shape reflective practitioners, recognizable by their ability to solve well-formed problems by applying evidence based knowledge and technique, with the associated artistry and practical adaptability that make it truly valuable (Schon, 1983).

This unprecedented potential, however, is accompanied by well-documented challenges. Increasing graduate debt, as well as income disparity between private practice and a career in education challenges institutions as they compete to recruit and retain high quality faculty (Livingston et al., 2004; Haden et al., 2000). For these reasons, among others, a major source of new dental education faculty come from the practicing community, looking to education as a rewarding second career (Hand, 2006). Although these veterans bring the strength of contextual ease, most lack pedagogical knowledge. This growing paradigm tests the notion that the quality of dental students' educational experience is critically dependent on an adequate number of committed faculty, possessing both content and teaching methodology expertise (Hand, 2006; Berliner, 1988; Benner, 2001; American Association of Dental Schools, 1999).

Given the prevailing conclusion that performers in a variety of domains need approximately ten years of intense involvement before they reach peak performance (Ericsson et al., 1993; Ericsson, 2008) the challenge of faculty development, especially that of the second career dental educator, becomes evident. Dental schools must recognize and support development of expertise in this valuable human resource, as efforts to recruit and retain a strong faculty are intensified. The success of our students, the care of our patients, and the health of our dental education system depends on effective implementation of the above issues.

It is surmised that having a general theory about the development of expertise, and data about the ways novices versus experts perform pedagogical tasks, may contribute to policy considerations benefiting faculty development (Berliner, 1988). Professors Hubert Dreyfus and Stuart Dreyfus describe such a path to competence as a theoretical continuum of skill acquisition; a learning process moving through distinct stages from novice to expert, the highest level of skill demonstrated by fluid performance based on previous situations without obvious thought (Dreyfus \& Dreyfus, 1986).

The purpose of this study was to explore development of teaching expertise utilizing the Dreyfus and Dreyfus construct of a continuum of skill acquisition (Dreyfus \& Dreyfus, 1986). A product of philosophical deliberation and phenomenological research, the Dreyfus model was adapted by Benner (2001) to explore skill acquisition in nursing (Benner). For this reason, among others, it appeared a logical construct to use to explore development of educators in another health care profession. By identifying what skill progression may be recognized in the expert dental educator; and 2.) What experiences appear to influence this growth, knowledge gained may help schools more efficiently and effectively support faculty development and lifelong learning. This paper begins with a theoretical framework of skill acquisition, provides and analyses qualitative data gathered through interviews of experienced dental educators, and explores skill progression revealed in this group of subjects. It offers both support of the literature, with regard to skill progression from novice to expert teaching, and findings that add to the literature. Lastly, questions for additional related research are suggested. 


\section{Theoretical Framework}

Professional dental education shares many traditional expectations of its professoriate as do most professions. Expressed by Rhodes, these include "the conviction that teaching is a moral vocation, that scholarship is a public trust, that service is a societal obligation and that an independent and open community is the essential means to both learning and discovery" (Rhodes, 1999, p. 37). Boyer proposes that the work of the professoriate might be thought of as having four distinct, intersecting functions: the scholarship of discovery; integration; application; and, finally, the scholarship of teaching, inferring that activities become impactful only when understood by others (Boyer, 1990). To that end, growing attention is being paid to the scholarship of teaching, which Smith defines as entailing a "public account of some or all of the full act of teaching - vision, design, enactment, outcomes, and analysis - open to peer review and benefit" (Smith, 2001, p. 69-70).

Faculty in the health care professions are called upon to grow practitioners who are less reliant on the opinion of others and more ready to utilize critical thinking and problem-solving skills to evaluate evidence and arrive at an independent decision (Strohschein et al., 2002; Roth, 2007). These same acquired skills are equally important to strong pedagogical abilities (Haden et al., 2006; Trotman et al., 2007).

\section{Skill Acquisition}

Researchers Hubert and Stuart Dreyfus proposed a theoretical model of skill acquisition reflecting a "progression from analytic behavior of a detached subject, consciously decomposing his environment into recognizable elements, and following abstract rules, to involved skilled behavior based on an accumulation of concrete experiences and the unconscious recognition of new situations as similar to whole remembered ones" (Dreyfus \& Dreyfus, 1986, p. 35). The five distinct stages of this learning process are described in Table 1.

Table 1

Five Stages of Skill Acquisition - Dreyfus and Dreyfus

\begin{tabular}{|c|c|c|c|}
\hline Skill Level & Components & Decision & Commitment \\
\hline Novice & Context-free & Analytical & Detached \\
\hline Advanced Beginner & Context-free and situational & Analytical & Detached \\
\hline Competent & Context-free and situational & Analytical & $\begin{array}{l}\text { Detached understanding } \\
\text { and deciding; Involved in } \\
\text { outcome }\end{array}$ \\
\hline Proficient & Context-free and situational & Analytical & $\begin{array}{l}\text { Involved understanding; } \\
\text { Detached deciding }\end{array}$ \\
\hline Expert & Context-free and situational & Intuitive & Involved \\
\hline
\end{tabular}

Adapted from Dreyfus and Dreyfus (1986, p.50)

Novice: The novice stage is characterized by recognition of relevant discrete facts, features, and rules for decision-making that are so clearly and objectively defined as to be 
virtually context-free (Dreyfus \& Dreyfus, 1986). Lacking a coherent sense of the overall task, the novice treats each situation as new and looks for appropriate rules to follow. Because the learner is without an experiential base, a forecast of expected outcomes must be provided, which do not rely on prior experience (Benner, 2004). Description of how textbook examples and actual application of this information relate is necessary and important (Benner, 2004).

A teacher at this stage of development may use rules and guidelines for designing a syllabus, delivering a lecture, leading a discussion, and presenting feedback (Smith, 2001). The novice teacher would likewise judge their own performance based on their adherence to learned action steps (Flyvbjerg, 2001).

Advanced Beginner: Progression to advanced beginner occurs only with significant practical experiences, the learner begins to perceive similarity of concrete situations with prior examples of the same experience. Actions can now be based on both the new situation and the earlier context-free components (Dreyfus \& Dreyfus, 1986).

No amount of verbal description provided at the advanced beginner level of learning is more productive than practical experience (Dreyfus \& Dreyfus, 1986). However, the educator can assist the student by formulating principles that dictate a particular action, thus creating a set of guidelines (Benner, 2001). Advanced beginners are keenly attuned to feedback and intently focused on the example of colleagues and mentors (Benner, 2014). The teacher at the advanced beginner level is newly able to recognize a poor classroom climate, uninspiring lecture, or confused students, then relies on rules to remedy the situation (Smith, 2001).

Competent Performer: The competent performer places a growing amount of situational experience and context-free rules into a problem-solving format by adopting a hierarchical process of decision making. (Dreyfus \& Dreyfus, 1986). Experts operate based on knowledge of several thousand such cataloged concrete cases in their area of expertise (Flyvbjerg, 2001). The speed with which competence increases is dependent upon the volume and complexities of learning experiences encountered (Benner, 2004).

While the competent performer may lack the efficiency of the more experienced performer, they are developing a growing ability to manage contingencies (Benner, 2001). Context becomes more critical. The learner develops a sense of when using rules is appropriate and when these rules provide diminishing returns and may be disregarded (Flyvbjerg, 2001).

The competent teacher chooses a goal or purpose to give focus to all information available and then works deliberately to simplify and solve the problem, anticipating or forecasting possible ramifications (Smith, 2001; Benner, 2004). Organizing curricula in ways that encourage conceptual understanding becomes beneficial to the student (Bransford et al., 2000). The new educator must begin to cultivate their ability to engage and interact with students, placing equal importance on developing knowledge, skills, and values (Benner, 2001).

Unlike the novice and advanced beginner, who react according to externally developed rules and, thus, feel little responsibility for outcomes, the competent performer becomes vested in outcomes resulting from his actions (Dreyfus \& Dreyfus, 1986). Reflection and outcome evaluation becomes important at higher levels of the learning process (Schon, 1983; Smith, 2001; Flyvbjerg, 2001).

Proficiency: Someone at the proficient level "while intuitively organizing and understanding his task, will find himself thinking analytically about what to do" (Dreyfus \& Dreyfus, 1986, p. 29). Situations are recognized simultaneously, judged to be similar or dissimilar to previous experiences, and acted upon in accordance with what actions have 
achieved successful outcomes in the past (Flyvbjerg, 2001). The situation guides the practitioner's response (Benner, 2004).

Case-based learning is of particular benefit at the proficient stage, particularly if the learner is asked to present specific examples and experiences that lead them to their chosen path or conclusion. Reflection on both good and less than desirable outcomes can stimulate effective learning (Benner, 2001). The proficient teacher intuitively identifies a problem then consciously analyses options to remedy it (Smith, 2001). "Learning to teach is an ongoing process of observing, reflecting and experimenting" (Pinsky et al., 1998, p. 215).

Expertise: The expert is fully engaged in fluid, efficient performance, responsive to context, based on previous situations, without obvious thought. "When things are proceeding normally, experts don't solve problems and don't make decisions; they do what normally works" (Dreyfus \& Dreyfus, 1986, p. 31; Chambers, 2012)). Responses are reactive rather than studied and premeditated. The expert performer engages in the situation, perceiving subtle changes and relying on a "creative search and cue sensitivity." Related to health care, based on genuine caring for the patient and ownership of outcomes, "It's not a question of choosing either science or practical wisdom, rather how to relate the two" (Benner, 2001, p. viii). In reflection, the expert focuses more on their intuition rather than the calculations they've made (Flyvbjerg, 2001).

Advances in neurophysics technology indicates that expert practitioners actually have "integrated neural networks that facilitate instantaneous retrieval of chains of knowledge relevant to task performance" which is very different from those of the novice (Hendricson, 2006, p. 5). Though this intuitive responsiveness may be an asset in many ways, an inability to break actions down into clearly verbalized, discrete elements can be an impediment to teaching novice students (Flyvbjerg, 2001). When experts are able to deconstruct and describe the significance of their actions, the student may more easily identify and learn from information embedded in their practice (Benner, 2001).

\section{Deliberate Practice and Reflection}

Ericsson (2008) describes an additional perspective, that expert performance may be traced to active engagement in deliberate practice, the process of continually stretching oneself with increasing goals and making time for serious self-assessment and reflection on personal performance (Ericsson).

Schon (1983) described, in complimentary terms, that professionals use a form of tacit experiential knowledge, which he terms knowing-in-action (Schon). He asserts that the most important competence, which aids the acquisition and continuous enhancement of all other competencies is reflection, the process of evaluating and learning from experience. He describes this activity taking place as reflection-in-action at the time one is engaged in an activity; and reflection-about-action after an activity (Schon, 1983). "Every attempt to produce an instruction is an experiment that tests both the coach's reflection on his own knowing-in-action and his understanding of the student's difficulty" (Schon, 1983, p. 104). Teaching "requires more than knowledge of theories and technical skills; it also requires analysis and reflective critique" (Smith, 2001, p. 76). 


\section{Methods}

This investigation sought to explore the nature of expert educator's skill and work patterns and to define how they are developed and manifested from the point of view of the educators themselves, and those who have recognized their abilities and nominated them for participation in this study. Grounded theory methodology was employed, utilizing qualitative data gathered through independent subject interviews. The study was approved with Exempt Status by the Institutional Review Board at the University of the Pacific.

Qualitative research involves "the studied use and collection of a variety of empirical materials - case study; personal experience; introspection; life story; interview; artifacts; cultural texts and productions; observation, historical, interactional, and visual texts - that describe routine and problematic moments and meanings in individual's lives" (Denzin \& Lincoln, 2003, p.5). "The qualitative researcher reviews social phenomena holistically [which] explains why [such] research studies appear as broad, panoramic, views rather than microanalysis" (Creswell, 2003, p.182). Wiersma and Jurs describe data analysis in qualitative research as "a process of categorization, description, and synthesis. Data reduction is necessary for the description and interpretations of the phenomenon under study" (Wiersma \& Jurs, 2005, p. 207).

In a type of qualitative approach that is participatory the researcher seeks to examine an issue by collecting stories from individuals who are interviewed at length to determine their personal experiences (Creswell, 2003). Individual interviews were utilized in this study to explore perceptions, investigate in depth events, activities, processes, and one or more individuals (Creswell).

Grounded theory methodology allowed the data gathered in this research to be analizeded for identification of common themes. Struass and Corbin describe qualitative analysis as involving the "nonmathematical process of interpretation, carried out for the purpose of discovering concepts and relationships in raw data and then reorganizing these into theoretical explanatory scheme" (Strauss \& Corbin, 1998, p.11). Theories or understandings emerge from the data gathered rather than data being to collected to confirm a pre-exisitng theory, as is more likely the case in guatatative studies (Charmaz, 2006, p. 5-6).

A purposeful sample was drawn from Academic Deans and experienced full-time dental school faculty in California. The literature (Ericsson, 1993) asserted that at least 10 years of practice was necessary to develop expertise so, for the purpose of this study, subjects studied had a minimum of ten years of teaching experience. This was defined as ten years or more of fulltime commitment to graduate level teaching in a professional program, in this case dentistry.

Academic Deans, from the five dental schools in California who had students enrolled at the time of this study, were introduced to the subject and purpose of this research. They were invited to take part in the study in two ways 1.) to participate as the subject of an independent interview and 2.) to nominate faculty, with a minimum of ten years of teaching experience, whom they identified as expert dental educators, for interview. Subjects eventually included three academic deans and seven experienced dental faculty, nominated by their academic deans. The specific areas of teaching focus of these educators varied, including didactic and clinical instruction or both (Table 2). In addition to their current administrative responsibilities, the three deans included in this study had deep teaching experience and continued to present content to students.

Journal of the Scholarship of Teaching and Learning, Vol. 15, No. 1, February 2015. 
Lyon, L.J.

Table 2

Subject Demographic Data

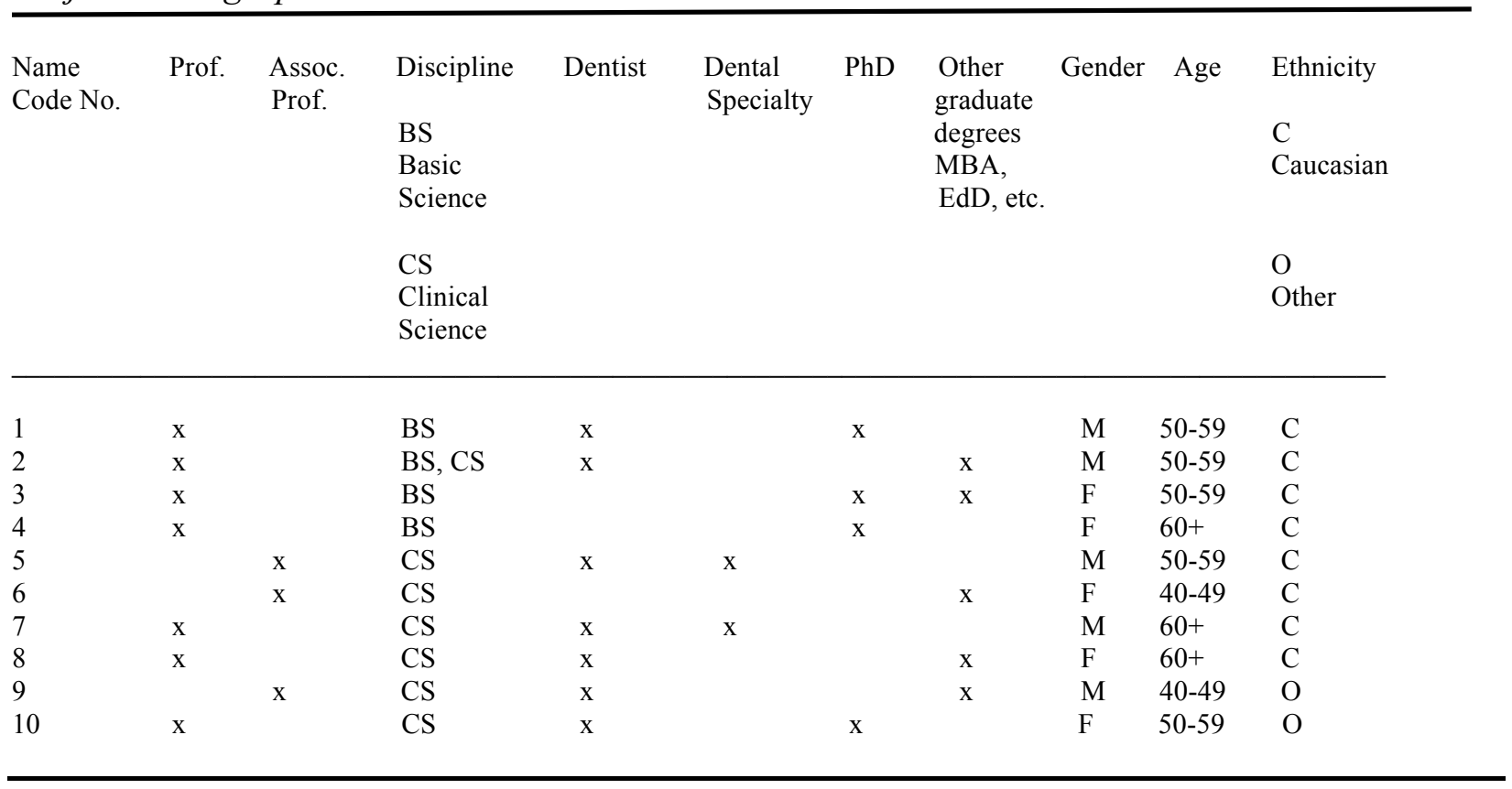

Detailed qualitative data was gathered via in-depth, open-ended interviews based on a standard set of questions. (See Appendix) Interviews, each approximately sixty minutes in length, were conducted by the primary investigator, either in person or by telephone. Although interview questions were slightly different for deans and faculty, responses were so similar that aggregating responses appeared more effective. Responses appeared to yield an in-depth description of the phenomenon being examined and enough variation in responses to illustrate a well-rounded picture. These were numbered to protect subject identity, transcribed verbatim, coded to identify and categorize segments of data, and further analyzed for identification of common themes.

\section{Findings}

Findings in the form of topics, dimensions, and categories describe skill progression perceived by these dental educators and provides a picture of experiences that appear to influence this growth process. Categories of Basic Knowledge, Functional Skills, Personal and Behavioral Qualities, and Reflection represent the main areas of observation or perception offered by subjects. The topics, which further emerged from the qualitative data gathered, serve to ground the categories noted (Table 3).

The categories were subsequently examined using the Dreyfus model to establish which were significant for different levels of novice to expert performance (Dreyfus \& Dreyfus, 1986). 
Lyon, L.J.

Table 3

Overview of Expert Faculty Codes

Category Topic

\begin{tabular}{|c|c|}
\hline \multicolumn{2}{|l|}{ A. Basic knowledge } \\
\hline A1. Content Specific & $\begin{array}{l}\text { a. Higher order content knowledge } \\
\text { b. Current with developments in their field } \\
\text { c. Habit of life-long learning }\end{array}$ \\
\hline A2. Application & $\begin{array}{l}\text { a. Loyalty to the learning process } \\
\text { b. Current with methodology developments } \\
\text { c. Ability to conceptualize, apply theory } \\
\text { d. Ability to synthesize, transfer knowledge } \\
\text { e. Aware of institutional curricular content and goals } \\
\text { f. Personal growth stimulated by constructive tension } \\
\text { g. Awareness of role models or mentors }\end{array}$ \\
\hline
\end{tabular}

B. Functional Skills

Dimensions

B1. Occupation Specific

a. Skilled in a variety of methodologies

b. Clear goals and expectations

c. Plans adequately

d. Assesses outcomes - formative/summative

e. Encourages student self-assessment

B2. Process

a. Considers the learner

b. Draws on personal experiences

c. Learning is the goal-rather than teaching

d. Brings context to the subject matter

e. Limits content - increases application

f. Connects the new or unknown to the known

g. Fosters critical thinking

h. Helps student think like an expert

i. Creates active learning opportunities

j. Challenges students in a non-threatening way

$k$. Innovates

\section{Personal and Behavioral Qualities}

Dimensions

C1. Vocational

a. Enthusiasm for the subject and the learning process

b. Highly Motivated - enjoys challenge

c. High standards

d. Commitment to personal excellence and growth

e. Willingness to take chances

f. Flexible in action

C2. Intraprofessional

a. Values collegiality

b. Stimulated by peers

c. Strong citizen of the educational community

$\begin{array}{ll}\text { D. Reflection } & \text { a. Reflects upon personal performance } \\ & b . \text { Reflects upon process } \\ & d . \text { Reflects out loud with students }\end{array}$

Journal of the Scholarship of Teaching and Learning, Vol. 15, No. 1, February 2015. 


\section{Basic Knowledge}

Dreyfus and Dreyfus (1980) define the first stage of learning, noted here by the term Basic, as context-free features which the beginner can recognize without benefit of experience" (p. 7). Acquisition of both basic content knowledge and the ability to apply it was recognized as the initial challenge faced by subjects. Interviewees recollected that their earliest teaching efforts revolved around mechanical presentation of unadorned content, almost to the exclusion of context. One subject confessed to:

". . . taking refuge in the facts" but noting that "providing that sort of [purely content] lecture was simple, but it was very unsatisfying. It quickly became boring, not only for the students, but for me". [1]

Acquisition of basic knowledge, and determination of its relevance within a growing sense of context, are among the earliest novice and advanced beginner experiences in the Dreyfus model, as is personal experience via trial and error. These seasoned educators almost universally described a beginning progression in concordance with this continuum.

As they brought greater context to the subject matter, faculty reported becoming better able to stimulate application of foundational knowledge. One recited a favorite quote from a $19^{\text {th }}$ century mathematician to underscore the importance of context over memorization of discrete facts:

A science is built of facts, just as a house is of bricks. But, a pile of facts is no more science than a pile of bricks is a house [1].

As they gained command of discipline knowledge and learned to prioritize information, faculty concentrated on teaching methodology. They began to approach presentation in a more holistic way, becoming increasingly aware of situational elements, including students' concurrent learning in other subject areas, influencing timely integration of their own content.

If you hook students in with a clinical scenario, they pay attention to the facts.

Whereas, if you put the facts first, they're kind of going, O.K., what's the point of all this stuff? [2]

From the perspective of recruiting professionals to academia, although these educators brought practical expertise in a given area, they did not commonly have formal education in basic teaching skills. This simultaneous differential where an individual may be at once expert with regard to certain problems and less skilled in other areas is recognized in the Dreyfus learning continuum. It is important to note that, at this early career stage, implicit expectations and formal, or informal, support of peers was deemed important to development.

\section{Functional Skills}

Dreyfus and Dreyfus (1980) propose that "competence comes only after considerable experience after coping with situations in which the student notes or the instructor points out recurrent, meaningful component patterns" (p. 8). For the purpose this study, this has been termed Functional knowledge. With initial exposure to teaching, higher order content knowledge developing, and growing utilization of varied teaching methodologies, awareness of the dynamics that students bring to the learning experience emerged. In the spirit of a decisionmaking and prioritization process, described by Dreyfus as typical of the competent performer, faculty reported the critical nature of recognizing what content was appropriate to the learner's 
level of understanding and then paring information down to its most important concepts; Less is more being the overarching sentiment.

Linking new concepts to known concepts was deemed critical, as was helping students differentiate pertinent from non-pertinent information. Describing their own personal growth being stimulated by constructive tension, there was apparent agreement that the learning environment, and the teacher, should challenge students in a non-threatening way. The ability to personalize teaching and learning approaches was believed especially important in situations where the student was having difficulty grasping a concept. These teachers challenged themselves to bring new ideas and concepts to their teaching, to innovate.

In the sense that the Dreyfus competent beginner struggles with the choice of plan and subsequently feels responsible for the outcome, assessment of learning outcomes assumed growing importance as these educators became more experienced. Although they conveyed pragmatic plans for the learning experiences, subjects' expression of outcomes alternated between highly structured and more broad and theoretical. All agreed that assessment was critical not only to confirming student learning, but also to developing strong teaching skills, informing progressive refinements as their careers progressed.

It's my opinion that learning is internal and individual, that each person comes to it in their own way. They have to have some commitment and involvement. So, the outcomes I look for are changed behavior in clinic. I look for changes to approaches in certain problems. [6]

I have a great deal of contact with students, especially in the lab. I listen for their conversations, check their reactions, and look at their faces. I depend on that a lot.

Students appreciate the opportunity to demonstrate what they know. [1]

Finally, helping learners self-assess was a recurring theme. With experience, subjects described a paradigm shift in their thinking about the purpose of their work. Student learning, rather than their own teaching, became their goal. While they understood more naturally the outcomes they hoped to achieve, they continued to reason analytically about how to obtain these.

With progression, subjects became better able to read and guide the learning experience, making adjustments smoothly and intuitively. They came to view students, and the learning process, in a more holistic fashion and felt responsible for, and deeply vested in, the success of both. As they assumed the level of proficient performers, although their actions became increasingly intuitive, they continued to reflect analytically on how to improve the process further, as the Dreyfus model might predict.

\section{Personal and Behavioral Qualities}

Personal and behavioral qualities appeared to compliment functional skills. Enthusiasm for subject matter, the learning process, and the challenges of staying abreast of both was displayed frequently by subjects.

Dentistry is so much more complex. 3D imaging will change the face of my specialty, as well as dentistry. The microscope has already [done that]. Technology has changed my specialty dramatically over the last ten years. So, it requires you to continually look for efficiencies in the way you deliver [content] because there's so much more to deliver. You can't get lazy. [7]

Experts displayed a commitment to personal excellence and growth. They held themselves and their students to a high standard, technically, morally, and ethically, and shared 
the rigors of their own personal development with students. These faculty seemed to take as a given that becoming professionally accomplished required not only high expectations, but a willingness to experiment, to be flexible in action, and take chances. One subject alluded to his increasingly intuitive ease with a more dynamic learning environment and his willingness to let class sessions unfold organically:

I plan less; my lectures have become much more organic. I just begin my story and see where it takes us. I have less need to know all of the answers. [1].

The group alluded to the importance of their community of learners. They appeared to interact intimately with peers, and to value the power of role models, mentoring, and camaraderie. With palpable affection and allegiance, several subjects spoke to this community:

I love the university atmosphere, there's no doubt. That kind of higher level thinking, when you can find it, is very stimulating. I gravitate towards individuals who constantly challenge your paradigms. [7]

Interviewees also held a high level of interest and concern for education beyond their personal classrooms, expressing a number of philosophical concerns, including patients' ability to receive services, academia's responsibility to provide care today, and to graduate professionals who will shape the future practice environment. Dreyfus and Dreyfus (1986, p. 30) reason that expert performers "see themselves as involved participants in a world of opportunities, threats, strengths, weaknesses, hopes, and fears." This concept appears to be confirmed by these senior educators whose professional views have become broad and holistic.

\section{Reflection}

Reflection appeared important to the growth of these individuals. Whether regarding personal performance, or the process of teaching, the cohort carefully considered their teaching and how to improve it. By design or example, most subjects incorporated expectations for student self-assessment and reflection in their learning plan. Some reflected out loud to help students learn by example. Dreyfus and Dreyfus (1986) reasoned that even within the context of a fluid, rational erformance, in order for continued learning to occur, some portion of the mind must remain detached and observational. It may be argued that without intentional reflection and improvement of process and outcome, skill acquisition may plateau.

An overview of the codes recognized - Basic Knowledge, Functional Skills, Personal and Behavioral Qualities, and Reflection - were viewed with the Dreyfus model of novice to expert development (Dreyfus \& Dreyfus, 1986). All five stages of the Dreyfus continuum from novice to expert were recognized (Table 4).

While outcomes find significant confirmation in the literature, study limitations include the following: relatively small sample size, limited number of schools, and subject self-reporting. Arguably the culture in which subjects teach may have an effect upon their development.

Future studies might include larger sample size, variety of schools and direct observation to confirm findings with actual behavior. Interviewing for self-reported perceptions is a direct approach for data gathering and provides important first step in identifying additional relevant issues. 


\title{
Table 4
}

Expertise in Dental Education: Codes Interpreted Relative to the Dreyfus and Dreyfus Model of Skill Acquisition

\footnotetext{
Novice: The novice recognizes clearly, objectively defined context-independent elements which are processed using externally provided rules and procedures to determine action. Difficulty forecasting outcomes based on lack of experience.

- Reliant on predetermined curriculum, course structure, and independent content elements.

Information delivered without significant context

(Codes: A1-a, A1-b)
}

\begin{abstract}
Advanced Beginner: The advanced beginner starts to recognize situational elements through experiential learning. External prompts remain important; however the advanced beginner is broadening understanding through experience which, at this stage is vastly more important than verbal description. Beginning to learn from mistakes.

- Reliant upon highly organized presentation of material, teaching experiences contribute to learning, observes experts in action (Codes: A2-b, A2-f, A2-g, C1-a)

- Recognizes the elements the learner brings to the environment (Codes: B2-a, B2-b)
\end{abstract}

Competent Performer: The competent performer develops the ability to prioritize overwhelming volumes of information and procedures in order to simplify and improve rational decision making. At this stage, the competent performer perceives responsibility and is vested in the outcomes of his performance.

- Gaining ability to conceptualize, synthesize, apply knowledge

(Codes: A2-a, A2-c, A2-d)

- Methodologies are becoming internalized; information is prioritized; a plan is created

(Codes: B1-a, B1-b, B1-c, B1-d, B2-e, B2-f)

- Assessments are structured analytically, outcomes become of increasing value; reflects on progress (Codes:B1-e, $\mathrm{Da}, \mathrm{Db})$

Proficient Performer: The proficient performer intuitively recognizes, organizes, and understand his task. The proficient performer continues to analyze options and make decisions about how to proceed based on reason

- Sees curricula more holistically, able to integrate subject matter

(Codes: A2-e, B2-i, Dd)

- Realizes the ability to make a difference. Learning becomes the goal rather than teaching. (Codes: B2-c, C1-b,)

Expert: The expert performer intuitively recognizes his task and fluidly reacts. They react fluidly and unconsciously. Rather than making decisions, they do what works based on experience and understanding.

- Teaching becomes instinctive, presentations more spontaneous, assessments more intuitive.

Creates constructive anxiety in the classroom.

(Codes: B2-g, B2-j, B2-k, C1-f)

- Methods include more experimentation. Understands that outcomes are not guaranteed

(Codes: C1-d, C1-e)

- Understands the importance of being a role model, inspiring the learner. Concerned for patient as

well as learner - communication with both is fluid and intuitive. Values ethic of patient care.

(Codes: B2-h, C1-c C2-c, Dc) 


\section{Conclusion}

The goal of this study was to explore skill progression recognizable in the expert dental educator and to learn more about the experiences supporting progression from novice to expert teaching.

\section{Findings that Find Confirmation in the Literature}

Results of this study indicate that novice dental educators experience many of the challenges described by Dreyfus and Dreyfus and others. Command of clinical expertise, which many new or second career faculty possess, is not the same skill as that of an educator. Simple accumulation of experience was the primary benefit to subjects' earliest teaching, followed by a growing recognition of context, environment, and learners' response. Novice faculty had simplistic ideas of how their content fits into the whole and were dependent on the example of mentors and role models (Schon, 1983; Haden et al., 2000; Berliner, 1988; Benner, 2001; Boyer, 1990; Smith, 2001; Haden et al., 2006; Trotman, 2007; Bransford et al., 2000; Pinsky et al., 1998; Hovland, 2002; Richlin, 2001; Forrest, 2006; Johnson \& Ridley, 2004; Schenkein \& Best, 2001; Wright \& Carrese, 2002).

As teaching skills progressed, faculty became increasingly aware of outcomes and their importance to the learning process. They experimented with assessment methods including guiding learner self-assessment. The process of consistent, formal outcomes assessment was viewed as critical to faculty development, as confirmed by a number of researchers (Dreyfus \& Dreyfus, 1986; Ericsson, 2008; Smith, 2001; Flyvbjerg, 2001; Pinsky et al., 1998; Hovland, 2002). Development of problem solving and critical thinking skills helped move both these developing faculty and their students from dependent to more self-directed life-long learning and action (Schon, 1983; Strohschein et al., 2002; Roth, 2007; Haden et al., 2006; Benner, 2004; Bransford et al., 2004; Hendricson et al., 2006). Many faculty also referenced constructive tension, within a humanistic atmosphere, as productive to personal growth and satisfaction in the academy, concepts supported in the literature (Rhodes, 1999; Haden et al., 2006; Pinsky et al., 1998). They voiced that personal growth and pivotal progression often occurred when they were forced to meet new challenges under stressful circumstances.

Finally, virtually all subjects displayed reflection-in-action and reflection-on-action described by Schon (1993). In the way that Ericsson (2008) reasoned that expert performers avoid arrested development by consistently striving for higher levels of achievement through deliberate practice, these faculty worked to continually improve as educators.

\section{Findings that add to previous studies}

Some unique challenges present themselves in the course of educating dental and other professional healthcare students. In addition to technique development, teachers convey noncognitive, interpersonal competencies such as professionalism, communication, and an ethic of care and service. The novice educator may benefit from teaching strategies displayed and described by subjects:

a) Stress context early in the learning process - excellent patient care is the goal

b) Expect students to apply foundational knowledge to clinical care, to make evidence based decisions 
c) Value and reinforce critical thinking, organizing information, and problem solving

d) Provide accessible skill-appropriate learning opportunities for the student

e) Engage students as actively as possible

f) Challenge students in a humanistic way

g) Assess formative and summative learning outcomes, both formally and informally

h) Help students recognize skills embedded in expert practice and connect these demonstrations with their own personal delivery of clinical care

i) Share personal experiences to connect explicit information with practical wisdom

j) Experiment with teaching methodologies to continually improve learning outcomes

k) Hold high expectations of students' capacity for learning and skill development

In addition to technical expertise, experienced faculty displayed personal and behavioral qualities, which enhanced their teaching and work satisfaction:

a) Enthusiasm for the learning process

b) Extraordinary levels of motivation

c) High standards and a commitment to personal excellence and growth

d) Passion for the academe, a genuine commitment to their peers and the educational community.

Dreyfus and Dreyfus asserted that a novice with inherent ability, given the opportunity to acquire a critical amount of experience, may become an expert. The experts studied additionally had highly-valued relationships with students and peers, and a positive learning environment. Professional challenge, stimulation, and ever-changing opportunities to develop mastery were equally motivating. Findings support supposition about qualities that attract an individual to education: professional challenge, a stimulating environment, endless variety of task, and opportunity for growth (Bertolami, 2007; Trower, 2007).

The collective reflections gained through interviews with expert dental educators provide an emerging profile of teaching expertise in dental education consistent with the Dreyfus skill acquisition continuum. The data gleaned opens conversation and prompts the following questions:

1.) How might development opportunities be better targeted to the educator's level of skill acquisition?

2.) How might faculty be better trained to utilize and model critical thinking?

3.) Would added focus on student learning assessment help educators advance more effectively?

4.) How might guided reflection reinforce positive qualities that inspire, challenge, and satisfy the individual educator?

5.) Do study findings have implications for faculty recruitment and retention strategies?

6.) Are there comparisons that should be explored between Novice to Expert stages of development and the traditional promotion and tenure model, timeline, and emphasis? Future research on these questions may build upon the findings revealed.

Subjects described personal growth, skill acquisition, attributes, assessments, and aspirations integral to development of teaching expertise in dental education. The Dreyfus model appeared descriptive of the learning sequence of the dental educator. Outcomes of this study may prove helpful to those actively involved in recruiting, challenging, developing, supporting, and enjoying life-long collegial relationships with dental and other healthcare educators at a myriad of points along their professional learning continuums. 


\section{Appendix}

\section{OPEN-ENDED STANDARD INTERVIEW QUESTIONS}

Interview Questions - Academic Dean Participants:

1. What attracted you to dental education?

2. What were your own milestones as an educator?

3. How do you recognize potential in new dental educators?

4. What faculty skills are important to student development?

5. How do you identity faculty with expertise?

6. Are there recognizable student learning milestones that denote faculty expertise?

7. What do you believe are the greatest challenges for dental educators?

8. Are there new challenges today in training students to become safe beginners?

9. What advise would you give a beginning educator?

Interview Questions - Dental Faculty Participants:

1. What inspired you to become a dental educator?

2. What are the core strategies you use to be an effective teacher of content?

3. What strategies do you use to be an effective teacher of students?

4. How do you know learning is going on?

5. Has your teaching changed over time? How?

6. What baseline skills, attitudes, or behaviors of expertise can you recognize in new students?

7. What advise would you give a beginning educator?

8. Is there anything else you would like to tell me? 


\section{References}

American Association of Dental Schools. (1999). Future of dental school faculty: Report of the president's task force. Washington DC: American Association of Dental Schools.

American Dental Association, Commission on Dental Accreditation. Accreditation. (n.d.). Retrieved from: http://www.ada.org/117.aspx

Benner, P. (2001). From novice to expert: Excellence and power in clinical nursing practice. Upper Saddle River, New Jersey: Prentice Hall.

Benner, P. (2004). Using the Dreyfus model of skill acquisition to describe and interpret skill acquisition and clinical judgment in nursing practice and education. Bulletin of Science, Technology and Society, 23(3), 188-199. doi: 10.1177/0270467604265061

Berliner, D. (1988). The development of expertise in pedagogy. Washington, DC: American Association of Colleges for Teacher Education Publications.

Bertolami, C. (2007). Creating the dental school faculty of the future: A guide for the perplexed. Journal of Dental Education, 71(10), 1267-1280.

Boyer, E. (1990). Scholarship reconsidered: Priorities of the professoriate. Princeton, NJ: The Carnegie Foundation for the Advancement of Teaching.

Bransford, J., Brown, A., \& Cocking, R. (Eds.). (2000). How people learn: Brain, mind, experience, and school. Washington, DC: National Academy Press.

Chambers, D. W. (2012). Dental education's involvement with dentists' learning in practice: Data and theory. Journal of Dental Education, 76, 107-117.

Charmaz, K. (2001). Constructing grounded theory: A practical guide through qualitative analysis. London: Sage Publications.

Creswell, J. (2003). Research design, qualitative, quantitative, and mixed methods approaches, $2^{\text {nd }}$ edition. Thousand Oaks: Sage Publications.

Denzin, N., \& Lincoln, Y. (Eds.). (2003). The landscape of qualitative research, theories and issues. Thousand Oaks: Sage Publications

Dreyfus, H., \& Dreyfus, S. (1980). A five-stage model of mental activities involved in directed skill acquisition. (Supported by the U.S. Air Force, Office of Scientific research (AFSC) under contract F49620-C-0063 with the University of California) Berkeley.

Dreyfus, H., \& Dreyfus, S. (1986). Mind over machine: The power of human intuition and expertise in the era of the computer. New York: Blackwell Publishers.

Journal of the Scholarship of Teaching and Learning, Vol. 15, No. 1, February 2015. 
Lyon, L.J.

Ericcson, K. A., Krampe, R. T., \& Tesch-Romer, C. (1993). The role of deliberate practice in the acquisition of expert performance. Psychological Review, 100(3), 363-406. doi: 10.1037/0033295X.100.3.363

Ericsson, K. A. (2008). Deliberate practice and acquisition of expert performance: A general overview. Academic Emergency Medicine, 15, 988-994. doi: 10.1111/j.1553-2712.2008.00227.x

Flyvbjerg, B. (2001). Making social science matter: Why social inquiry fails and how it can succeed again. Cambridge, UK: Cambridge University Press. doi: 10.1017/CBO9780511810503

Forrest J. (2006). Treatment plan for integrating evidence-based decision making into dental education. Journal of Evidence Based Dental Practice, 6(1), 72-78. doi:

10.1016/j.jebdp.2005.12.022

Haden, K., Andrieu, S., Chadwick, D., Chmar, J., Cole, J., George, M., et al. (2006). The dental education environment. Journal of Dental Education, 70(12), 12165-12170.

Haden, K., Beemsterboer, P. L., Weaver, R. G, Valachovic, R. W. (2000). Dental school faculty shortages increase: An update on future dental school faculty. Journal of Dental Education, 64(9), 657-673.

Hand, J. (2006). Identification of competencies for effective dental faculty. Journal of Dental Education, 70(9), 937-947.

Hendricson, W., Anderson, E., Andrieu, S., Chadwick, D., Cole, J., George, M., et al. (2007). Does faculty development enhance teaching effectiveness? Journal of Dental Education, 71(12), 1513-11533.

Hendricson, W., Andrieu, S., Chadwick, D., Chmar, J., Cole, J., George, M., et al. (2006). Educational strategies associated with development of problem-solving, critical thinking, and self-directed learning. Journal of Dental Education, 70(9), 925-936.

Hovland, E. (2002). Introduction: Dental school's relations with organized dentistry and accreditation: The Gies report reconsidered. Journal of the American College of Dentists, 69(2), 13-17.

Johnson, W., \& Ridley, C. (2004). Elements of mentoring. New York. Palgrave Macmillan.

Livingston, H., Dellinger, T., Hyde, J., \& Holder, R. (2004). The aging and diminishing dental faculty. Journal of Dental Education, 68(3), 346-354.

Pinsky, L. E., Monson, D., \& Irby, D. M. (1998). How excellent teachers are made: Reflecting on success to improve teaching. Advances in Health Sciences Education, 3, 207-215. doi: 10.1023/A:1009749323352 
Lyon, L.J.

Rhodes, F. H. T. (1999). Thoughts on the American university at the dawn of the third millennium. Retrieved from: http://theuniversityfaculty.cornell.edu/forums/pdfs/Rhodes.pdf

Rhodes, F. H. T. (2001). The creation of the future: The role of the American university. Ithaca, NY: Cornell University Press.

Richlin, L. (2001). Scholarly teaching and the scholarship of teaching. New Directions for Teaching and Learning, 86, 57-68. doi: 10.1002/t1.16

Roth, K. (2007). Dental education: A leadership challenge for dental educators and practitioners. Journal of Dental Education, 71(8), 983-987.

Schenkein, H., \& Best, A. (2001). Factors considered by new faculty in their decision to choose careers in academic dentistry. Journal of Dental Education, 65(9), 832-840.

Schon, D. (1983). The reflective practitioner: How professionals think in action. New York: Basic Books.

Smith, R. (2001). Expertise and the scholarship of teaching. New Directions for Teaching and Learning, 86, 69-78. doi: 10.1002/tl.17

Strohschein, J., Hagler, P., \& May, L. (2002). Assessing the need for change in clinical education practices. Physical Therapy, 82(2), 160-172.

Struass, A, L., \& Corbin, J. M. (1998). Basics of qualitative research: Techniques and procedures for developing grounded theory. Thousand Oaks, CA: Sage Publications.

Trotman, C., Haden, K., \& Hendricson, W. (2007). Does the dental school work environment promote successful academic careers? Journal of Dental Education, 71(6), 713-725.

Trower, C. (2007). Making academic dentistry more attractive to new teacher-scholars. Journal of Dental Education, 71(5), 601-605.

Wiersma, W., \& Jurs, S. (2005). Research methods in education: An introduction, $8^{\text {th }}$ Edition. Boston: Pearson A and B.

Wright, S. M., \& Carrese, J. A. (2002). Excellence in role modeling: Insight and perspectives from the pros. Canadian Medical Association Journal, 167(6), 638-643. 